\title{
Optimalisasi Peran Bidan Dalam Tata laksana Awal Preeklampsia Di Pekanbaru
}

\section{${ }^{1}$ Donel Suhaimi, ${ }^{2}$ Dhini Aiyulie Novri, ${ }^{3}$ Maya Savira}

\author{
${ }^{1,2}$ Obstetrics and Gynaecology Department, Faculty of Medicine, University of Riau / Arifin Achmad \\ Regional Hospital of Riau Province, Indonesia \\ ${ }^{3}$ Microbiology Department, Faculty of Medicine, University of Riau, Indonesia \\ email: 1donelmy@yahoo.com
}

\begin{abstract}
Eclampsia and pre-eclampsia are the leading causes of death in pregnancy in Indonesia. Midwives are the first-line providers of maternal and child health services. Therefore, the knowledge and skills of a midwife regarding the initial management of pre-eclampsia and eclampsia are very important in order to reduce maternal mortality. Activities to optimize the role of midwives as first-line health providers in the initial management of preeclampsia and eclampsia cases are held online. This seminar was successfully held on September 25, 2020, with 417 participants. Most of the participants came from cities in Riau, but there were also those from the east such as Makassar and Denpasar. The series of events were in the form of a pretest, delivery of material by experts (obstetricians and gynecologists), post-tests, and question and answer sessions. There is an increase in the knowledge of midwives about the diagnosis and initial management of preeclampsia cases through this seminar which is assessed through increasing score of pretest to the post test.
\end{abstract}

Keywords: eclampsia, midwives, pre-eclampsia

\begin{abstract}
Abstrak. Eklampsia dan preeklamsia merupakan penyebab utama kematian pada kehamilan di Indonesia. Bidan merupakan pemberi pelayanan kesehatan ibu dan anak lini pertama. Oleh karena itu, pengetahuan dan keterampilan bidan mengenai tata laksana awal preeklamsia dan eklampsia sangat penting dalam menurunkan angka kematian ibu. Kegiatan untuk mengoptimalkan peran bidan sebagai tenaga kesehatan lini pertama dalam penanganan awal kasus preeklamsia dan eklampsia ini dilakukan secara daring. Seminar ini diselenggarakan pada tanggal 25 September 2020 dengan jumlah peserta 417 orang. Sebagian besar peserta berasal dari kota-kota di Riau, namun ada juga yang berasal dari timur seperti Makasar dan Denpasar. Rangkaian kegiatan terdiri dari sesi berupa pre-tes, penyampaian materi oleh para ahli (dokter kandungan dan ginekolog), post-test, dan sesi tanya jawab. Terdapat peningkatan pengetahuan bidan tentang diagnosis dan tata laksana awal kasus preeklamsia melalui seminar ini yang dinilai melalui peningkatan skor pada saat pre-tes ke post-tes.
\end{abstract}

Kata kunci: bidan, eklampsia, pre-eklampsia

\section{Pendahuluan}

Gangguan hipertensi dalam kehamilan terjadi sekitar $5-10 \%$ dari seluruh kehamilan dan merupakan salah satu dari tiga penyebab utama kematian dalam kehamilan, selain perdarahan dan infeksi (Vest et al. 2012). Sepuluh tahun yang lalu, penyebab kematian maternal didominasi oleh perdarahan, sedangkan saat ini mayoritasnya disebabkan oleh preeklampsia dan eklampsia. Bidan sebagai pemberi pelayanan kesehatan ibu dan anak merupakan lini pertama dalam 
memberikan pelayanan dasar kepada ibu, diberikan kewenangan untuk melayani ibu dalam kondisi gawat darurat untuk kemudian dirujuk ke rumah sakit yang lebih lengkap sarananya.

Maka dari itu, pengetahuan dan kecakapan seorang bidan mengenai tata laksana awal preeklampsia dan eklampsia sangatlah penting sebagai penanggung jawab lini pertama bagi ibu hamil guna menurunkan angka kematian ibu. Selama ini, bidan yang menerima ibu hamil dengan tekanan darah tinggi kebanyakan bingung untuk melakukan tatal aksana awal pasien dengan preeklampsia. Banyak bidan yang menyuruh pasien langsung pergi ke rumah sakit tanpa melakukan tata laksana awal. Hal ini menjadi serius ketika pasien yang akhirnya pulang, memilih untuk tetap di rumah. Akibatnya, pasien bisa mengalami kejang. Penyakit ini berkontribusi besar terhadap morbiditas dan mortalitas ibu selama kehamilan (Peralta et al. 2016).

Task Force of the American College of Obstetricians and Gynecologists menggambarkan empat tipe penyakit hipertensi dalam kehamilan yaitu sindroma preeklampsia dan eklampsia; hipertensi kronis; preeklampsia superimposed hipertensi kronis; dan hipertensi gestasional (Cunningham et al. 2018)

Sindroma preeklampsia dengan hipertensi kronis adalah yang paling berbahaya. Preeklampsia berkontribusi sekitar 3,9 persen dari seluruh kehamilan (Berhe. 2018). Di negara berkembang, preeklampsia terjadi sekitar 1,8\% hingga $16,3 \%$ pada seluruh kehamilan. World Health Organization (WHO) melaporkan bahwa sekitar $15 \%$ dari kematian ibu di dunia berasal dari komplikasi hipertensi dalam kehamilan (WHO. 2019). Patofisiologi hipertensi akibat kehamilan masih belum dipahami sepenuhnya meskipun pada dekade terakhir penelitian intensif banyak dilakukan. Gangguan hipertensi tetap belum terpecahkan di antara masalah-masalah penting dan menarik di bidang kebidanan (American College of Obstetricians an Gynecologist. 2017).

Sindrom preeklampsia dan eklampsia masih merupakan penyebab utama kematian ibu disamping infeksi dan perdarahan, oleh karena itu diagnosis dini preeklampsia harus lebih ditingkatkan untuk mencegah terjadinya sindrom preeklampsia dan eklampsia dan menurunkan angka kematian ibu5. Penyebab kematian ibu telah diklasifikasikan dalam 3 fase keterlambatan, yaitu: Fase 1, kegagalan pasien untuk mendapatkan perawatan medis yang tepat pada waktu dibutuhkan; fase 2, keterlambatan dalam mencapai fasilitas perawatan kesehatan yang adekuat; fase 3, terlambat menerima penanganan kesehatan yang adekuat pada fasilitas kesehatan yang tersedia, termasuk keterlambatan dalam rujukan (Unicef. 2018).

Dari tahun 2000-2017, rasio kematian ibu menurun secara global sebesar 38 persen, dari 342 kematian menjadi 211 kematian per 100.000 kelahiran hidup. Ini berarti tingkat pengurangan tahunan rata-rata mencapai 2,9 persen. Meskipun bermakna, nilai ini masih kurang dari setengah dari nilai yang dibutuhkan setiap tahunnya $(6,4$ persen) demi meraih target Sustainable Development Goals (SDGs), yang mana target SDGs adalah 70 kematian ibu per 100.000 kelahiran hidup (WHO. 2019). Tiga etiologi mayor dari mortalitas maternal adalah perdarahan, hipertensi, dan sepsis. Kelainan tekanan darah pada wanita hamil salah satunya adalah preeklampsia (Unicef. 2018).

Diagnosis yang ditegakkan secara dini dan tata laksana terstandar dapat mengurangi angka insidensi dan menurunkan angka morbiditas ibu preeklampsia berat (PEB) dan eklampsia (Kemenkes RI. 2018). Bidan sebagai tenaga kesehatan lini pertama seharusnya mampu mengenali sejak awal serta memberikan tata laksana awal 
yang terstandar terhadap pasien PEB dan eklampsia sebelum dirujuk ke fasilitas kesehatan/rumah sakit dengan fasilitas yang lebih lengkap. Ketidakmampuan bidan dalam mendiagnosis dan menata laksana preeklampsia di fasilitas kesehatan (lini pertama) berperan dalam peningkatan kasus kematian akibat preeklampsia ataupun eklampsia (Clinical Obstetrics: The Fetus \& Mother. 2007).

Kejadian eklampsia dapat dicegah dengan perawatan kehamilan yang memadai, sehingga kejadian eklampsia telah menurun beberapa tahun terakhir. Di negara maju, angka kejadian 1:2000 (Bartsch et al. 2016), sedangkan angka kejadian di Inggris 1:2000 menurut Royal College of Obstetricians and Gynaecologists (2006), Akkawi dkk. tahun 2009 di Dublin angka kejadian 1:2500, Andersgaard dkk. di Skandinavia angka kejadian 1:2000, dan Zwart dkk. di Belanda 1:1600 kejadian (Cunningham et al. 2018). Meskipun penyebab preeklampsia masih belum diketahui, dampaknya dimulai sejak awal kehamilan (Ward et al. 2014). Perubahan ini pada akhirnya melibatkan multi-organ dengan dimulai dengan gejala klinis yang hampir tidak terlihat sampai pada kerusakan dahsyat yang dapat mengancam kehidupan ibu dan janin (Beckmann. 2019). Hipertensi pada kehamilan terbukti meningkat pada wanita yang terpapar villi korionik untuk pertama kalinya, terpapar cilli korionik dalam jumlah banyak, memiliki riwayat penyakit yang berhubungan dengan aktivasi atau inflamasi sel endotel, dan memiliki riwayat faktor genetik/ keturunan dengan hipertensi pada kehamilan (Cunningham et al. 2018).

Preeklampsi masih dapat terjadi meskipun villi chorionic tidak berada di dalam cavum uteri. Sebagai contoh, Worley dkk. melaporkan kejadian preeklampsia pada wanita dengan kehamilan extrauterine melebihi usia kehamilan 18 minggu (Worley et al.
2008).

Abnormalitas antara jaringan ibu, plasenta, dan janin dapat menyebabkan preeklampsia. Preeklampsia melibatkan sejumlah faktor dari ibu, plasenta, dan janin.

Meskipun penyebab preeklampsia masih belum diketahui, dampaknya dimulai sejak awal kehamilan. Perubahan ini pada akhirnya melibatkan multi-organ, dimulai dengan gejala klinis yang hampir tidak terlihat sampai pada kerusakan dahsyat yang dapat mengancam kehidupan ibu dan janin. Seperti telah dibahas, ini diakibatkan oleh vasospasme, disfungsi endotel, dan iskemia. Segudang fenomena pada ibu akibat sindrom preeklampsi biasanya dijelaskan dalam sistem organ individu, dengan gejala klinis yang hampir tumpang tindih (Beckham et al. 2019).

Hipertensi dalam kehamilan ditata laksana berdasarkan derajat keparahan, usia gestasi, dan ada atau tidaknya preeklampsia (American College of Obstetricians an Gynecologist.. 2017). Adapun target utama penatalaksanaan kehamilan yang disertai dengan penyakit preeklampsia adalah(Cunningham et al. 2018):

a. Mengakhiri kehamilan dengan komplikasi seminimal mungkin bagi ibu dan janinnya

b. Lahirnya neonatus yang kemudian dapat bertumbuh-kembang dengan baik

c. Kesehatan ibu yang kembali pulih.

Prinsip tata laksana preeklampsia berat, yaitu3 pengendalian kejang dengan magnesium sulfat intravena loading dose, diikuti dengan maintenance dose; pemberian obat antihipertensi untuk menurunkan tekanan darah kapan saja jika dipertimbangkan berbahaya; menghindari diuretic dan pembatasan pemberian cairan intravnea kecuali apabila pengeluaran cairan berlebihan; dan persalinan. Sasaran seminar ini adalah bidan yang memiliki praktik bidan mandiri dan bidan yang bertugas 
di Puskesmas. Dengan adanya kegiatan ini, diharapkan pengetahuan bidan akan meningkat mengenai preeklampsia. Dengan meningkatnya pengetahuan, bidan akan lebih percaya diri untuk mengedukasi pasien mengenai tindakan lanjutan bahkan dapat menata laksana awal pasien dengan regimen sulfas magnesikus. Pemberian tata laksana awal tersebut sangatlah berarti bagi status kesehatan ibu ke depannya. Tak hanya itu, hal ini akan menekan perburukan kasus preeklampsia dan secara tidak langsung menekan angka kematian ibu. Berdasarkan hal di atas, maka kami melakukan kegiatan optimalisasi bidan dalam tata laksana awal kasus preeklampsia.

\section{Metode Ilmiah}

Dalam upaya penekanan angka kematian ibu, perlu dilibatkan partisipasi aktif dari seluruh kalangan medis ataupun non medis di Indonesia. Angka kematian ibu, merupakan salah satu indikator yang ingin dicapai dalam penentuan kesejahteraan suatu Negara. Di Indonesia, mayoritas angka kematian ibu disebabkan oleh hipertensi dalam kehamilan (sindrom preeklampsia), perdarahan, dan infeksi.

Indonesia, merupakan suatu Negara yang luas dengan angka kehamilan yang masih tinggi dibandingkan dengan Negara maju. Dewasa ini, tata laksana kasus preeklampsia mengalami update yang pesat. Namun hal ini, tidak diiringi dengan pemerataan dokter spesialis kandungan dan kebidanan di seluruh pelosok negeri. Bidan merupakan profesi yang khusus menangani ibu hamil. Bidan hingga saat ini dianggap sebagai elemen tenaga kesehatan yang paling dekat dengan ibu hamil serta tersedia lebih merata di seluruh daerah sentral maupun perifer di Indonesia. Saat ini, mayoritas ibu hamil masih lebih sering melakukan antenatal care atau kontrol kehamilan dengan bidan dibandingkan dengan dokter spesialis. Sehingga, peningkatan tekanan darah pada pasien kemungkinan pertama kali diketahui oleh bidan.

Dengan data di atas, bidan memegang potensi yang amat kuat dalam mencegah perburukan dan progresivitas kasus preeklampsia pada seorang ibu hamil. Namun, hal ini menjadi buruk ketika bidan tidak memiliki pengetahuan yang cukup update dalam tata laksana awal kasus preeklampsia. Dengan pengetahuan dasar yang dimilikinya, seyogianya seorang bidan harus mampu mendiagnosis, menata laksana awal, mengedukasi, serta merujuk pasiennya secara optimal.

Tujuan kegiatan ini adalah mengoptimalkan peran bidan dalam tatalaksana awal kasus prekklampsia. Indikator ketercapaian program adalah sebagai berikut:

a. Jangka pendek adalah meningkatnya pengetahuan bidan setelah acara seminar berlangsung. Hal ini dibuktikan dengan peningkatan pengetahuan bidan antara pretest dengan posttest.

b. Jangka menengah (hitungan bulan) adalah semakin baiknya sistem rujukan kasus preeklampsia oleh bidan ke fasilitas kesehatan lanjutan. Diharapkan, semua pasien dengan preeklampsia telah diberikan sulfas magnesikus sesuai persyaratan sebelum dirujuk oleh bidan.

c. Jangka panjang adalah menurunnya angka kematian ibu akibat kesalahan ataupun keterlambatan perujukan kasus preeklampsia.

Adapun manfaat kegiatan ini adalah sebagai berikut:

a. Bagi bidan

Sarana belajar untuk mengoptimalkan perannya sebagai provider kesehatan lini pertama dalam tata laksana awal kasus preeklampsia dan eklampsia. Bidan yang sudah dilatih nantinya 
akan dapat melatih bidan pustu (puskesmas pembantu), serta kader Posyandu setempat mengenai tatalaksana awal kasus preeklampsia.

b. Bagi pelaksana

Menjalankan salah satu tugas tri dharma perguruan tinggi dalam bentuk pengabdian kepada masyarakat.

c. Bagi masyarakat

Meningkatnya status kesehatan masyarakat dengan adanya tenaga kesehatan yang terampil dan berpengetahuan terstandar dalam menangani kasus preeklampsia dan eklampsia. Bidan yang merupakan sasaran dalam kegiatan ini, tentunya akan meningkat pengetahuannya. Meningkatnya pengetahuan bidan terlatih, bidan pustu, dan kader Posyandu tentunya akan meningkatkan status kesehatan masyarakat.

Sasaran kegiatan ini adalah bidan yang berfungsi sebagai pelayan kesehatan lini pertama yang paling dekat aksesnya dengan ibu hamil. Pekanbaru tergolong dalam zona hitam pandemik COVID-19 saat kegiatan ini berlangsung, sehingga diputuskan untuk melakukan kegiatan optimalisasi ini secara online atau daring dengan skala nasional menggunakan media Zoom dan Youtube. Acara ini dilakukan dengan host berada di Fakultas Kedokteran Universitas Riau agar menjamin koneksi internet yang baik serta kelancaran acara webinar. Persiapan acara dimulai dengan persiapan narasumber yang mumpuni untuk memberikan materi terkait dengan kasus preeklampsia. Setelah itu, dibuat flyer elektronik yang disebar melalui media sosial. Penyebaran flyer dilakukan sejak 2 minggu sebelum acara dimulai. Tentu saja, flyer disebar pada komunitas yang dekat dengan profesi bidan. Hingga akhirnya terkumpul 417 peserta seIndonesia.
Pendaftaran dilakukan mandiri oleh peserta secara daring dengan menggunakan sistem otomatis. Teknis pendaftaran tertera pada flyer yang dibagikan. Agar mempermudah teknis dan komunikasi ketika acara, para peserta dimasukkan ke dalam satu grup Whatsapp. Setelah peserta terjaring dan melakukan pemetaan terhadap peserta, tim kemudian berkumpul untuk menyusun pretest dan posttest bagi peserta. Masing-masing berisi 10 soal yang mewakili pengetahuan mengenai diagnosis dan tata laksana awal kasus preeklampsia bagi bidan. Webinar ini dilakukan pada tanggal 24 September 2020 pada pukul 14.00 sampai pukul 16.00 WIB.

Webinar dilaksanakan secara daring dengan durasi 2 jam. Diawali dengan pretest pada pagi hari sebelum webinar agar dapat mengukur tingkat pengetahuan peserta webinar. Pretest dilakukan secara daring menggunakan aplikasi Google Form. Teknis pengisian pretest dijelaskan pada grup Whatsapp yang telah dibuat sebelumnya. Webinar dilaksanakan pada siang harinya. Materi kemudian disampaikan langsung oleh Dr. dr. Donel, SpOG(K) dengan bahasa yang komunikatif untuk seluruh audiens seminar dengan judul "Optimalisasi Peran Bidan dalam Tatalaksana Awal Preeklampsia”. Setelah materi, kami juga menyediakan posttest untuk menilai peningkatan pengetahuan. Setelah materi disampaikan, dilakukan sesi tanya jawab dan posttest. Lalu dilakukan analisa perbandingan jawaban peserta sebelum dan sesudah pemberian materi.

\section{Hasil dan Pembahasan}

Sasaran kegiatan ini adalah medis khususnya bidan yang berfungsi sebagai tenaga kesehatan yang paling dekat dengan ibu hamil.

Hal ini menjadi serius ketika pasien yang akhirnya pulang, memilih untuk tetap di rumah. Akibatnya, pasien 
bisa mengalami kejang. Hal seperti ini seharusnya tidak terjadi apabila bidan memiliki pengetahuan yang cukup mengenai preeklampsia dan mengerti mengenai diagnosis dan tata laksana kasus preeklampsia. Apalagi, preeklampsia merupakan ilmu yang sangat berkembang dan selalu tersedia update setiap saat.

Sasaran seminar ini adalah bidan. Dengan ini, diharapkan pengetahuan bidan akan meningkat perannya dalam menata laksana awal pasien dengan preeklampsia. Dengan meningkatnya pengetahuan, bidan akan lebih percaya diri untuk mengedukasi pasien mengenai tindakan lanjutan bahkan dapat menata laksana awal pasien dengan regimen sulfas magnesikus. Pemberiantata laksana awal tersebut sangatlah berarti bagi status kesehatan ibu ke depannya. Tak hanya itu, hal ini akan menekan perburukan kasus preeklampsia dan secara tidak langsung menekan angka kematian ibu. Hingga saat ini, preeklampsia-eklampsia masih merupakan penyebab mayor mortalitas ibu hamil di seluruh dunia, khususnya Indonesia.

ini $\begin{array}{ccc}\text { Kegiatan } & \text { seminar } & \text { online } \\ \text { dianggap } & \text { sebagai } & \text { solusi }\end{array}$ untuk meningkatkan pengetahuan bidan mengenai tatalaksana kasus preeklampsia. Tim kami menjaring sebanyak mungkin bidan di seluruh Indonesia untuk mengikuti seminar ini. Rangkaian kegiatan dimulai dengan penyebaran pamflet acara di seluruh media sosial oleh tim, institusi setempat, dan institusi terkait untuk menjaring bidan sebanyak mungkin.

Setelah melakukan penjaringan, terkumpul sebanyak 417 peserta seminar online yang kemudian kami kumpulkan dengan grup Whatsapp agar dapat memantau peserta seminar dengan baik serta menyediakan solusi jika terdapat kendala ketika seminar online berlangsung.

Pada seminar ini, kami menitik beratkan mengenai cara mendiagnosis dan menata laksana awal kasus preeklampsia. Mengenai materi diagnosis, kami memaparkan diagnosis banding pada preeklampsia, parameter yang dibutuhkan untuk menyingkirkan diagnosis banding, dan cara menegakkan diagnosis kasus preeklampsia sesuai dengan update terbaru oleh American Congress of Obstetric and Gynaecology. Untuk materi tatalaksana awal, kami mendemonstrasikan secara langsung mengenai pilihan obat antihipertensi yang aman untuk digunakan pada fasilitas kesehatan lini pertama (praktik bidan), dosis, cara pemberian, serta pengawasan setelah pemberian obat. Selain itu, kami juga menegaskan pentingnya pemberian regimen sulfas magnesikus pada pasien dengan preeklampsia berat.

Sesi tanya jawab berlangsung cukup lama, yaitu sekitar 1 jam untuk menjawab pertanyaan terkait materi oleh peserta webinar. Selain itu, kami juga memberikan materi seminar kepada seluruh bidan yang dapat diakses oleh para bidan lain. Hal ini dilakukan dengan harapan agar bidan peserta seminar daring ini dapat meneruskan ilmu yang diterimanya kepada kader, junior bidan, serta sejawat bidan lain tempat mereka bertugas.

Dan terbukti pada akhir kegiatan, terdapat peningkatan tingkat ketepatan bidan dalam mendiagnosis dan menentukan tindak lanjut pada ibu hamil dengan eclampsia. Dari nilai rerata pretes 38 menjadi 89 (post tes) pada penentuan tatalaksana awal; dan nilai 61,2 menjadi 78.7 dalam penegakan diagnosis preeklampsia. Acara berlangsung lancar dengan antusiasme tinggi dari peserta. Sesi tanya jawab dapat dilaksanakan secara optimal dikarenakan terdapat banyak pertanyaan dan apresiasi dari peserta webinar.

\section{Kesimpulan dan Saran}

Dari pembahasan yang sudah dilakMelalui seminar daring ini, kami 
mendapatkan peningkatan pengetahuan bidan mengenai diagnosis dan tata laksana awal kasus preeklampsia di fasilitas kesehatan pertama yang dibuktikan dengan meningkatnya nilai/ score posttest dibandingkan dengan pretes. Kegiatan ini hendaknya dilakukan berkesinambungan dan berkelanjutan untuk meningkatkan luaran kasus preeklampsia pada khususnya, dan kasus obstetri ginekologi lain pada umumnya. Metode ini dianggap efektif, serta sangat cocok untuk diterapkan pada situasi pandemi Covid-19.

\section{DAFTAR PUSTAKA}

Vest AR, Cho LS. Hypertension in Pregnancy. Cardiol Clin. 2012;30(3):407-23.

Rosas-peralta M. Hipertensión durante el embarazo: el reto continúa. Rev Med Inst Mex Seguro Soc. 2016;54(111):90.

Cunningham, F. Gary, Leveno, Kenneth J., Bloom, Steven L., Dashe, Jodi S., Spong, Catherine Y. et al. Williams Obstetrics, 25th Edition. New York: McGraw-Hill Education; 2018.

BerheAK, Kassa GM, Fekadu GA, Muche AA. Prevalence of hypertensive disorders of pregnancy in Ethiopia: A systemic review and meta-analysis. BMC Pregnancy Childbirth. 2018;18(1):1-11.

World Health Organization. Maternal mortality [Internet]. Vol. 72, Journal of the Kentucky Medical Association. 2019. Available from: https://www.who.int/newsroom/fact-sheets/detail/maternalmortality

American College of Obstetricians an Gynecologist. Emergent Therapy for Acute-Onset, Severe Hypertension During Pregnancy and the Postpartum Period. 2017;129(640):e90-5.
UNICEF. Maternal mortality rates and statistics - UNICEF DATA [Internet]. UNICEF Data: Monitoring the situation of children and women. 2019. p. 1-8. Available from: https://data. unicef.org/topic/maternal-health/ maternal-mortality/

Kemenkes RI. Profil Kesehatan Indonesia 2018. Science as Culture. 2018;1(4):146-7.

Reece EA, Hobbins JC, editors. Clinical Obstetrics: The Fetus \& Mother. 3rd ed. Victoria: Blackwell Publishing; 2007.

Bartsch E, Medcalf KE, Park AL, Ray JG, Al-Rubaie ZTA, Askie LM, et al. Clinical risk factors for preeclampsia determined in early pregnancy: Systematic review and meta-analysis of large cohort studies. BMJ. 2016;353.

Ward K, Taylor RN. Genetic factors in the etiology of preeclampsia/ eclampsia [Internet]. Fourth Edition. Chesley's Hypertensive Disorders in Pregnancy, Fourth Edition. Elsevier Inc.; 2014. 57-80 p. Available from: http://dx.doi. org/10.1016/B978-0-12-4078666.00004-3

Beckmann CRB, Ling FW, Herbert WNP. Obstetrics and Gynecology. 8th ed. Wolters Kluwer Health; 2019.

Worley KC, Hnat MD, Cunningham FG. Advanced extrauterine pregnancy: diagnostic and therapeutic challenges. Am J Obstet Gynecol. 2008;198(3):297.e1-297.e7. 